\title{
A CONSTRUÇÃO SOCIAL DO MERCADO EM DURKHEIM E WEBER: análise do papel das instituições na sociologia econômica clássica*
}

\section{Cécile Raud-Mattedi}

\section{Introdução}

Desde a década de 1980, a sociologia econômica está em plena efervescência nos Estados Unidos e na Europa. ${ }^{1}$ Cada vez mais sociólogos estão

* Este texto foi escrito durante o estagio pós-doutoral realizado entre ago. 2002-jul. 2003 na Universidade de Dauphine, Paris, França. Gostaríamos de agradecer à Capes, pelo apoio financeiro, à professora Catherine Bidou, diretora do Iris, que nos convidou e nos disponibilizou ótimas condições de trabalho e, sobretudo, ao professor Philippe Steiner, nosso orientador, cuja contribuição foi fundamental para a elaboração deste texto. Agradecemos também ao professor Fernando Ponte de Sousa e aos demais colegas pelos comentários a respeito de uma versão preliminar deste texto, discutida num dos seminários internos do Programa de Pós-Graduação em Sociologia Política da UFSC.

Artigo recebido em abril/2004

Aprovado em novembro/2004 empenhados em analisar os fatos econômicos de maneira a fornecer explicações alternativas às teorias econômicas, sobretudo à teoria standard neoclássica. Em particular, esta "nova sociologia econômica" teria o mérito de analisar sociologicamente o núcleo mesmo da ciência econômica, ou seja, o mercado, o que a distinguiria radicalmente da sociologia econômica clássica (Swedberg, 1994). No entanto, outros autores criticam essa noção de ruptura e defendem a idéia de que, na sociologia econômica de hoje e de ontem, o objetivo e os meios permanecem os mesmos (Gislain e Steiner, 1995).

De fato, a sociologia econômica surge no final do século XIX em reação à hegemonia da teoria econômica marginalista e aos limites evidentes de seu programa de pesquisa (Idem). Teóricos da envergadura de Durkheim, Weber, Simmel ou Veblen, por exemplo, tentam denunciar os pressupostos teóricos e metodológicos de uma ciência 
social que se reivindica independente do meio social. $^{2}$ Sem se limitar a este papel crítico, eles aplicam seu próprio modelo analítico ao estudo dos fenômenos econômicos.

Este texto pretende resgatar, de maneira exploratória, algumas reflexões pioneiras de Durkheim e Weber a respeito do mercado a fim de poder tomar posição no quadro desse debate. Não pretendemos discutir a existência de uma continuidade ou de uma ruptura entre a nova e a velha sociologia econômica. Gostaríamos apenas de argumentar, contra Swedberg (1994), que Durkheim e Weber iniciaram o estudo sociológico do mercado em termos de construção social, contribuindo assim diretamente para a emergência da nova sociologia econômica na década de 1970. Ambos refletiram sobre o papel das instituições na orientação do comportamento do ator econômico e, portanto, na regulação do mercado, com conclusões freqüentemente semelhantes.

Para organizar nossa argumentação, escolhemos tomar como ponto de partida uma classificação emprestada de Weber, provavelmente o sociólogo clássico que foi mais longe na analise sociológica do mercado, e contrastar com a posição de Durkheim. Além de sua tipologia bem conhecida da ação social, Weber dá uma pista rápida, mas extremamente interessante, dos diversos tipos possíveis de regulação do mercado. No segundo capítulo da primeira parte de Economia e sociedade, intitulado "As categorias sociológicas fundamentais da gestão econômica”, considerado por Swedberg (1998a) como seu manifesto em sociologia econômica, Weber explica que a regulação do mercado pode ter quatro tipos de causa: tradicional, convencional, jurídica ou voluntária (Weber, 1991). Essa tipologia nos permite abordar os temas da tradição, das regras morais e das regras jurídicas, aos quais acrescentamos uma análise do papel do Estado para além do Direito. Antes, no entanto, abordaremos uma questão preliminar, qual seja, a definição sociológica do mercado, que implica a análise de sua dimensão socializadora.

\section{Uma definição sociológica do mercado}

Apesar de sua crítica aos economistas, acusados de utilizar pré-noções, isto é, conceitos econômicos que não foram definidos cientificamente, mas que fazem parte do senso comum, ${ }^{3}$ Durkheim não define realmente o que ele entende por mercado. No entanto, ele não deixa de considerar este fenômeno econômico como uma instituição, ou seja, um fato social. Para Steiner (1992) é esta abordagem institucional que caracteriza, de maneira geral, a sociologia econômica durkheimiana e dos durkheimianos. De fato, Durkheim identifica o mercado como uma das "instituições relativas à troca”, no quadro de sua definição da sociologia econômica como sociologia específica que analisa as instituições relativas à produção de riquezas, à troca e à distribuição (Durkheim, 1975, p. 135). Além disso, no cerne de sua análise do mercado encontra-se a noção de contrato, cuja importância veremos em seguida. A sociedade moderna é fundamentalmente uma sociedade de mercado, ou seja, contratual: "a cada instante e não raro inesperadamente, sucede-nos contrair esses vínculos, seja ao comprarmos, seja ao vendermos [...]. A maioria das nossas relações com outrem são de natureza contratual" (Idem, 1995, p. 201). ${ }^{4}$ Nesse sentido, apesar de Durkheim não usar freqüentemente o termo "mercado", quando analisa o contrato, o que ocorre freqüentemente em sua obra, ele está se referindo à esfera do mercado. Partimos, portanto, do pressuposto de que a sociologia durkheimiana do mercado podia ser deduzida de sua análise do contrato na sociedade moderna.

Apesar desta definição sucinta do mercado, Durkheim traz uma contribuição fundamental à sociologia do mercado, na medida em que mostra o papel socializador da troca mercantil no quadro da divisão social do trabalho (Steiner, 1992). Com efeito, apesar de suas conquistas evidentes, a nova sociologia econômica, com seu esforço para reafirmar a dimensão social da economia, acaba às vezes assumindo uma visão "intimista" do laço social. "Dito de outra forma, a confiança, baseada em relações pessoais contínuas e duráveis, representa a condição de possibilidade da troca mer- 
cantil concreta. Mas esta concepção parece limitar nossa compreensão da especificidade do laço social mercantil" (Chantelat, 2002, p. 522). ${ }^{5}$ Nesse sentido, Durkheim deu algumas pistas para pensar a especificidade sociológica da relação mercantil. De fato, a coesão social no âmbito da solidariedade orgânica nasce das interdependências decorrentes da especialização e da divisão do trabalho. A sociedade moderna prescinde da forte consciência coletiva, que assegura a coesão social nas sociedades tradicionais, onde não há divisão do trabalho. Portanto, a relação mercantil, que obriga pessoas a entrar no mercado para trocar bens e serviços indispensáveis à sua sobrevivência, encerra uma dimensão socializadora. No entanto, isto não ocorre espontaneamente, como pretendem Spencer e os economistas liberais. Portanto, a ordem social não decorre da busca egoísta de seu interesse por parte de cada indivíduo isolado. "Para que cooperem harmoniosamente [...] é necessário [...] que as condições dessa cooperação sejam estabelecidas para toda a duração de suas relações", e isto será feito por regras formais (jurídicas) e/ou informais (tradição, normas) (Durkheim, 1995, p. 200).

Essa referência à importância do direito contratual ou das regras informais na regulação do mercado será analisada mais tarde. Por enquanto, o que nos interessa são as conseqüências sociais da troca mercantil. Se o mercado funcionasse como dizem os liberais, só resultaria uma "solidariedade precária", uma vez que seria baseada numa relação social mercantil superficial, conflitual e instável:

Se o interesse aproxima os homens, nunca o faz mais que por alguns instantes e só pode criar entre eles um vínculo exterior [...]. As consciências são postas apenas superficialmente em contato: nem se penetram, nem aderem fortemente umas às outras. Se olharmos as coisas a fundo, veremos que toda harmonia de interesses encerra um conflito latente ou simplesmente adiado. Porque, onde o interesse reina sozinho, como nada vem refrear os egoísmos em presença, cada eu se encontra face ao outro em pé de guerra e uma trégua nesse eterno antagonismo não poderia ser de longa duração. De fato, o interesse é o que há de menos constante no mundo (Idem, p. 189).
Mas, na medida em que o ator econômico se enquadra na regulamentação contratual, isto é, na medida em que respeita uma série de regras sociais, seja formais (direito), seja informais (tradição e normas morais), elaboradas coletivamente e inscritas numa dimensão temporal de longo prazo, ele participa da criação de uma verdadeira relação social:

[...] mesmo onde a sociedade repousa da maneira mais completa na divisão do trabalho, ela não se resolve numa poeira de átomos justapostos, entre os quais só se podem estabelecer contatos externos e passageiros. Mas seus membros são unidos por vínculos que se estendem muito além dos momentos tão curtos em que a troca se consuma (Idem, p. 217).

Portanto, a relação mercantil gera um laço social mesmo sem passar por relações pessoais íntimas, na medida em que esse laço não se esgota no único ato da troca, mas se enraíza e participa do processo de reprodução das instituições sociais.

Weber, por sua vez, na sua cuidadosa análise das categorias sociológicas fundamentais da economia, não deixa de definir, mesmo que de maneira sucinta, sua concepção de mercado. "Falamos de mercado quando pelo menos por um lado há uma pluralidade de interessados que competem por oportunidades de troca”, assim o "[...] fenômeno específico do mercado [é] o regateio" (Weber, 1991, p. 419). Weber via o mercado como o resultado de duas formas de interação social - a troca, que está simultaneamente orientada para o parceiro e para os concorrentes, e a competição (luta sobre os preços entre o cliente e o vendedor e entre concorrentes, tanto vendedores como clientes). Estabelece-se então uma idéia fundamental em relação à visão econômica do mercado, qual seja, a noção de luta ${ }^{6}$ e, conseqüentemente, de poder, que introduz uma dimensão política no coração de um fenômeno econômico. ${ }^{7}$ No mercado encontram-se em conflito interesses opostos, e a troca efetivada representa uma situação de equilíbrio.

A troca é um compromisso de interesses entre os participantes pelo qual se entregam bens ou possibilidades como retribuição recíproca. [...] Toda 
troca racionalmente orientada é a conclusão mediante um compromisso de uma prévia luta de interesses aberta ou latente (Idem, p. 43). ${ }^{8}$

Nesse sentido, os preços expressam as relações de poder existentes entre os atores econômicos: eles provêm de "[...] luta (luta de preços e de concorrência) e de compromisso entre interesses diversos que ocorrem no mercado" (Idem, p. 57).

Weber aprofunda sua análise sociológica do mercado, mostrando que ele "[...] representa uma coexistência e seqüência de relações associativas racionais, das quais cada uma é especificamente efêmera por extinguir-se com a entrega dos bens de troca" (Idem, p. 419). Dizer que se trata de atos reiterados é analisar o mercado como forma de interação social e introduzir uma dimensão temporal ausente de muitos modelos econômicos. Por outro lado, o impacto socializador da relação mercantil na visão weberiana do mercado é limitado pela dimensão "efêmera" da troca e pelo número limitado de atores contemplados: "a troca realizada constitui uma relação associativa apenas com a parte contrária na troca" (Idem, ibidem). No entanto, Weber nega uma concepção tradicional do mercado, ou seja, o atomismo dos atores econômicos, na medida em que tanto o produtor como o cliente levam em conta a concorrência.? No período preparatório anterior à troca, "ambos os interessados na troca orientam suas ofertas pela ação potencial de uma pluralidade indeterminada de outros interessados também concorrentes, reais ou imaginados" (Idem, ibidem).

Além disso, como em Durkheim, a relação mercantil é uma relação social na sociologia econômica weberiana, uma vez que o ator econômico deve levar em conta não somente o comportamento dos outros atores econômicos, mas também, de maneira mais geral, o contexto sociopolítico. ${ }^{10}$ De fato, a atividade econômica orientase em função de interesses próprios ${ }^{11}$ "[...] e também pela ação futura e previsível de terceiros [...], além disso por aquelas 'ordens' que o agente conhece como leis e convenções 'em vigor'" (Idem, p. 20). O restante do texto concentra-se na análise dessas leis e convenções que orientam o comportamento econômico.

\section{As diversas instituições sociais de regulação do mercado}

$\mathrm{Na}$ sociologia econômica de Durkheim, e esta afirmação pode ser aplicada igualmente à sociologia weberiana, "as instituições organizam as relações sociais e as atividades econômicas, não somente porque regulamentam os conflitos de interesse, mas sobretudo porque permitem a definição mesma dos interesses individuais" (Trigilia, 2002, pp. 76-77). Nesse sentido, deve-se entender as instituições em termos de regras, formais ou informais, e de valores.

Ambos analisam o papel das instituições na regulação do mercado, contudo o significado das instituições não é o mesmo para Durkheim e para Weber. Se as instituições determinam o comportamento dos indivíduos em Durkheim, elas o orientam em Weber. Com efeito, para ele, não é a norma em si que explica a ação social, mas a apropriação que o ator social faz desta norma. De fato, a norma pode influenciar a conduta com diferentes graus de consciência: costume, cálculo utilitário ou respeito valorativo da norma (Weber, 1977).

Durkheim desenvolve uma análise das instituições econômicas que pode ser caracterizada em termos de "custos de transação", para usar uma terminologia contemporânea. De fato, em sua análise da divisão do trabalho, ele dialoga com Spencer e os economistas marginalistas, criticando a visão deles de uma sociedade organizada com base no único contrato mercantil, e mostra que a estabilidade do sistema de troca generalizada, que constitui a sociedade moderna, depende do respeito a regras preestabelecidas. Devido à inconsistência do interesse, o contrato puro implica um custo alto em termos de tempo social para a (re)negociação sistemática das cláusulas, quando da sua formação ou do surgimento de conflitos. Portanto, a viabilidade do contrato, como relação mercantil generalizada, depende de um fundo institucional composto, de um lado, pelos costumes mentais e comportamentos enraizados na repetição da troca ao longo do tempo e, de outro lado, pelas regras jurídicas, que não são nada mais que a cristalização de costumes mentais e comportamentais do passado (Durkheim, 1995). 
De acordo com Weber (1991, pp. 17-18), o sociólogo não se interessa tanto pelas ações individuais e sim pela análise de diversos "tipos de regularidades na atividade social", ou seja, para falar como Durkheim, pela análise das instituições. No quadro de seu método compreensivo, Weber (1991) distingue, entre os motivos dos diversos tipos de regularidades sociais, a busca do interesse mútuo, o respeito a uma regra tradicional, uma convenção social ou uma regra jurídica. Encontramos aqui, além da busca do interesse ${ }^{12}$ (tema que não cabe tratar neste texto), as três instituições fundamentais de regulação do mercado: o uso/costume, a convenção e o Direito, às quais acrescentaremos uma reflexão mais geral sobre o papel do Estado para além do Direito.

\section{O papel da tradição na construção social do mercado}

Weber define o uso a partir do momento em que a probabilidade de uma determinada regularidade decorre unicamente do "exercício efetivo", e o uso se torna costume quando "[...] o exercício se baseia no hábito inveterado" (1991, p. 18). A diferença com relação à convenção ou ao Direito reside no fato de que o indivíduo pode escolher livremente se conformar ou não ao costume, sem que haja qualquer caráter de obrigatoriedade ou punição. Pode-se dizer que o mercado é regulado pela tradição quando é determinado "[...] pela assimilação de limitações ou condições tradicionais da troca" (Idem, p. 50). É evidente para Weber que uma regulação pela tradição ou por convenções é contrária ao espírito racional da economia: "A troca pode ser ambicionada e realizada: 1) de forma tradicional ou convencional e, portanto, irracional, do ponto de vista econômico [...], ou 2) de forma racional, economicamente orientada" (Idem, p. 43).

De maneira geral, Weber contrapõe constantemente capitalismo e tradicionalismo econômico, em particular em sua Historia geral da economia, em que mostra o papel da religião e das estruturas sociais, como as castas ou os clãs na manutenção das mesmas técnicas e práticas de trabalho (1968). No entanto, ainda que a modernidade seja caracterizada por uma racionalização crescente, a tradição não desapareceu completamente: "mesmo com considerável racionalização da ação, a influência exercida pela orientação tradicional permanece relativamente importante" (Idem, p. 41). Em particular, a existência de uma necessidade, por exemplo o desejo de adquirir um bem, é determinada em grande medida pela tradição.

Durkheim não distingue claramente a tradição das normas sociais na sua análise do contrato, mas não deixa de mostrar que os atores econômicos não podem buscar somente seus interesses, pois devem respeitar também certas regras costumeiras.

Enfim, fora dessa pressão organizada e definida que o direito exerce, há uma outra que vem dos costumes. Na maneira como celebramos nossos contratos e como os executamos, somos obrigados a nos conformar com regras que, por não serem sancionadas, nem direta, nem indiretamente, por nenhum código, nem por isso são menos imperativas. Há obrigações profissionais puramente morais, e que no entanto são bastante estritas (Durkheim, 1995, pp. 202-203).

De fato, percebemos que, apesar de terem feito referência à importância da tradição no comportamento do ator econômico e na regulação do mercado, nenhum dos dois autores desenvolveu sua análise nesse sentido. Em contrapartida, quando se trata das regras morais ou jurídicas, encontramos uma reflexão mais aprofundada em ambos.

O papel das normas sociais: legitimidade dos interesses individuais e justiça social

Uma outra fonte das regularidades são para Weber as convenções sociais, definidas como um “[...] 'costume' que, no interior de determinado círculo de pessoas, é tido como 'vigente' e está garantido pela reprovação de um comportamento discordante" (Weber, 1991, p. 21). A noção importante apresentada nessa definição, e que distingue a convenção da tradição, é a reprovação social. O ator social é obrigado a se conformar à determinada convenção social se ele não quer sofrer as con- 
seqüências do "boicote social". ${ }^{13}$ Essa influência não é sentida somente na esfera social, especialmente nas classes altas da sociedade, mas também na esfera econômica. Em particular, no mercado, existe uma "[...] desaprovação social da mercabilidade de determinadas utilidades ou da livre luta de preços e de concorrência para determinados objetos de troca ou para determinados círculos de pessoas" (Idem, p. 50). ${ }^{14}$

Por um lado, Weber não parece ter desenvolvido uma análise sistemática sobre o papel das normas sociais, ou convenções, na economia moderna, em particular na regulação do mercado. Ele se limitou, em diversos momentos de Economia e sociedade, a abordar rápido e indiretamente esse tema. Veremos, assim, quando analisarmos a relação entre mercado e Direito, que este último tem um papel regulador menos importante do que as convenções, ou melhor, ele é respeitado essencialmente em função de uma convenção social que reprova a desobediência civil. Em outras passagens, o autor parece negar a influência das normas sociais, definindo o mercado "livre" como um mercado "não comprometido por normas éticas" (Idem, p. 420). A única ética existente no mercado, segundo Weber, é o respeito à palavra dada, sem o qual as transações financeiras na bolsa, por exemplo, seriam impossíveis. É esta dificuldade de qualquer regulamentação ética do mercado que explicaria a antipatia profunda tanto da religião católica como do protestantismo luterano em relação ao capitalismo (Weber, 1968, p. 312). Weber faz referência ao princípio do "preço justo", mas apenas para mostrar que ele faz parte do passado, uma vez que caracteriza a ética econômica medieval. De maneira geral, o autor opõe ao espírito do capitalismo moderno o espírito do tradicionalismo econômico, caracterizado por um forte componente ético. Nele os diversos aspectos da produção, da distribuição e do consumo são definidos por convenções sociais, geralmente legitimadas pela religião. De fato, Weber considera que o mercado moderno representa "relações impessoais" entre os seres humanos. Como é dominado por interesses materiais individuais, tal mercado é contrário a toda "confraternização", à "piedade" e à "comunidade". ${ }^{15}$ As relações comu- nitárias representam, pois, "obstáculos" para o desenvolvimento do mercado (Weber, 1991, p. 420). É justamente quando desapareceu o dualismo ético, ou seja, quando foi superada a oposição entre ética interna baseada na reciprocidade e ética externa aberta ao lucro, que o mercado pôde se desenvolver (Trigilia, 2002).

Por outro lado, apesar de reconhecer a importância da busca do interesse para explicar o comportamento do ator econômico, Weber não cai na armadilha do pensamento liberal, pois não deixa de apontar o papel norteador das idéias: "são interesses (materiais e morais) e não idéias que a princípio comandam a maneira de agir dos homens. No entanto, as visões do mundo criadas por 'idéias' freqüentemente orientaram as ações humanas sobre as vias determinadas pelo dinamismo dos interesses" (Weber, 1960, pp. 18-19), ou seja, nossa "visão do mundo" acaba condicionando nossos interesses. De fato, toda sua obra empenha-se em mostrar que os interesses e os meios adequados para satisfazê-los são situados social e historicamente, já que devem ser legitimados pelos valores existentes na sociedade. Assim, a economia de mercado só existe e se mantém no quadro de uma sociedade que incentiva a busca racional do lucro e onde reina uma certa ética do trabalho. Nesse sentido, não se pode pensar que os interesses sejam os únicos elementos explicativos do comportamento do ator econômico e do funcionamento do mercado, pois os interesses precisam dos valores para a formulação de seus objetivos e para a legitimação dos meios empregados para persegui-los.

Considerações éticas entram na sociologia econômica de Weber também quando o autor distingue entre racionalidade formal da economia e racionalidade material. Se a primeira refere-se à aplicação rigorosa da lógica fria do cálculo de custo e benefício, a segunda permite introduzir uma avaliação valorativa das conseqüências sociais da atividade econômica. A "racionalidade formal" de uma atividade econômica tem a ver com "[...] o grau de cálculo tecnicamente possível e que ela realmente aplica", ou seja, uma atividade econômica será considerada "formalmente racional" à medida que suas "previdências" possam 
ser quantificadas (Weber, 1991, p. 52). Nesse sentido, a economia moderna é o arquétipo da atividade econômica formalmente racional, na medida em que é orientada para o lucro, que supõe o calculo monetário, "meio formalmente mais racional de orientação da ação econômica” (Idem, p. 53). A racionalidade material, em contrapartida, garante a possibilidade de se avaliar a atividade econômica sob outros pontos de vista. Exigências éticas, políticas, de classe, igualitárias etc., podem ser mobilizadas para apreciar a atividade econômica no contexto de uma racionalidade em valor ou de uma racionalidade material em finalidade. ${ }^{16}$ Nesse sentido, essa racionalidade avalia os resultados da atividade econômica em termos de repartição dos bens entre os diversos grupos sociais, em termos de hierarquia social, ou ainda em termos de outros critérios de valor. ${ }^{17}$ Weber acrescenta que essas duas formas de racionalidade "[...] discrepam, em princípio, em todas as circunstâncias", mesmo que possa ocorrer ocasionalmente uma coincidência (Idem, p. 68).

No que tange às relações entre economia e moral, Durkheim adota uma postura ao mesmo tempo normativa e analítica. Por um lado, o autor adverte quanto aos riscos da modernidade, ao insistir sobre o estado de anarquia de uma sociedade cuja esfera econômica não está regulada moralmente (Durkheim, 1983, 1995). De maneira geral, a sociologia durkheimiana aborda o tema das regras morais na vida econômica com base na noção de anomia, lamentando as conseqüências mórbidas da ausência de regras morais, no caso da divisão do trabalho, por exemplo (Idem, 1995). Por outro lado, na polêmica que mantém com Spencer e os economistas marginalistas, o autor se empenha em mostrar que a moral não é tão ausente assim da vida econômica, mesmo na sociedade moderna. Ele analisa particularmente a moral profissional (Idem, 1983), mas aborda também o tema do mercado (Idem, 1995). Nesse sentido, não se pode opor a sociedade tradicional, caracterizada por uma forte consciência coletiva, à sociedade moderna, cuja solidariedade derivaria somente das interdependências nascidas da divisão do trabalho. Com efeito, a especialização profissional e os contratos têm uma "moralidade in- trínseca", na medida em que, como atores econômicos, "[...] somos pegos numa rede de obrigações de que não temos o direito de nos emancipar" (Idem, 1995, pp. 218 e 219). A moral, uma dessas instituições que o ator econômico deve respeitar, desempenha várias funções na sociologia econômica durkheimiana.

Em primeiro lugar, o papel das regras morais é de permitir a passagem do nível micro ao nível macro, ou seja, de realizar a adequação entre os interesses individuais e os interesses coletivos. De fato, para Durkheim, fazer do ser humano (egoísta) um ser social (moral) supõe uma instituição que o obrigue a respeitar e se conformar aos interesses sociais, isto é, supõe uma disciplina moral, internalizada por meio do processo de socialização. Assim, diferentemente do que afirma a teoria liberal, Durkheim mostra que o bem-estar coletivo não pode decorrer da busca egoísta dos interesses individuais. Pelo contrário, existe um antagonismo entre ambos, pois, sem disciplina moral, a sede de riqueza é sem fim (Idem, 1983).

Em segundo lugar, as regras morais são fundamentais para a estabilidade da sociedade contratual, uma vez que asseguram o respeito às instituições básicas. Durkheim mostra a origem religiosa do respeito aos contratos e à propriedade privada, por meio das palavras e dos ritos religiosos, quando da emergência histórica dessas instituições. Mas hoje, com a diminuição da fé, o que asseguraria o respeito ao contrato, instituição básica do mercado? É evidente que o direito obriga as partes interessadas, mas, fundamentalmente, o contrato é sagrado porque o indivíduo é sagrado. Da mesma forma, é a emergência do individualismo ${ }^{18}$ que explica o caráter sagrado da propriedade individual, outra instituição fundamental da sociedade mercantil. Originalmente, havia uma "religiosidade difusa nas coisas", que, aos poucos, passou a caracterizar as pessoas: “[...] as coisas deixaram de ser sagradas por si mesmas, já não tiveram esse caráter senão indiretamente, pois dependiam das pessoas, estas sim, sagradas" (Idem, p. 156). A referência a uma esfera transcendente, sagrada, corporifica-se nos ritos, não somente verbais, como no caso do formalismo religioso e jurídico, mas também manuais: ainda 
hoje o aperto de mão ou uma refeição/bebida compartilhada costumam selar os contratos. Talvez a significação primitiva desses ritos tenha se perdido, mas a tradição se mantém (Idem, 1983). Assim, as regras morais permitem assegurar a confiança no mercado, mesmo entre pessoas que não se conhecem diretamente, pelo respeito aos mesmos valores fundamentais da sociedade moderna, ou seja, os direitos do indivíduo.

Finalmente, percebemos que as regras morais difundem também um princípio de justiça que orienta a vida econômica de maneira geral e que influencia, em particular, o estabelecimento dos contratos e dos preços. De fato, juntamente com o respeito ao contrato, o individualismo traz princípios novos, a saber, as noções de livre consentimento e, sobretudo, de contrato justo.

Negligenciadas pelos economistas, as "condições morais da troca” requerem uma regulação do mercado que não se limite a perseguir as fraudes e a fazer respeitar os contratos, mas que aja eficazmente contra os desequilíbrios que acarretam uma troca injusta e geram conflitos, pondo em perigo as próprias atividades econômicas (Trigilia, 2002, p. 79).

Esta dimensão moral supõe, primeiro, que ninguém pode ser obrigado a assinar um contrato e, segundo, que o contrato não deve prejudicar nenhuma parte. Aqui Durkheim se refere a um aspecto psicológico - os sentimentos de simpatia que os seres humanos sentem em relação ao outro -, mas que expressa uma norma social típica da sociedade moderna, ou seja, o respeito ao indivíduo. É esse respeito que fundamenta a condenação coletiva da injustiça. "Há, nessa exploração do homem pelo homem [...], algo que nos ofende e nos indigna" (Durkheim, 1983, p. 192). Nesse contexto, a consciência social rebela-se contra o contrato injusto, o que pode diminuir a pressão para que ele seja respeitado. ${ }^{19}$ "Reprovamos todo contrato leonino, isto é, todo contrato que favoreça indevidamente uma parte em detrimento da outra; por conseguinte, julgamos que a sociedade não está obrigada a fazê-lo respeitar" (Idem, pp. 192-193). Durkheim reconhece que tais julgamentos morais ainda não influenciaram devidamente o Direito, mas mostra que um progresso nítido pode ser sentido no caso do mercado do trabalho, no qual uma série de medidas, efetivas ou propostas, como o salário mínimo, o seguro-doença, a aposentadoria etc., estão começando a "[...] tornar menos injusto o contrato de trabalho" (Idem, p. 193).

Essa noção de contrato justo, ou eqüitativo, faz intervir uma idéia extremamente interessante em sociologia econômica, a noção de preço justo. "É sabido, com efeito, a existência em cada sociedade, e em cada momento da história, de um sentimento obscuro, mas vivo, do valor dos vários serviços sociais, e das coisas envolvidas nas trocas" (Idem, p. 191). Por um lado, Durkheim faz referência ao mecanismo de formação dos preços, mecanismo essencialmente social e não mercantil: "os preços verdadeiros das coisas trocadas são fixados anteriormente aos contratos, bem longe de resultar deles" (Idem, p. 192). O autor continua sua reflexão explicitando sua noção do valor dos bens, que se afasta da teoria do valor-trabalho da economia clássica e marxista, e se aproxima da noção de utilidade da economia neoclássica:

[...] não é a quantidade de trabalho posto numa coisa que lhe faz o valor a essa coisa, é a maneira pela qual essa coisa é estimada pela sociedade; e essa estimativa depende não tanto da quantidade de energia despendida quanto de seus efeitos úteis, tais, ao menos, como são sentidos pela coletividade (Idem, p. 197).

Infelizmente, Durkheim não aprofunda este tema da "construção social do preço", remetendo a reflexão a um momento mais oportuno. Por outro lado, ele mostra como as normas sociais - isto é, morais - orientam o mercado, na medida em que a sociedade reprova o contrato injusto, como acabamos de ver, ou seja, um contrato que prevê a remuneração de bens ou serviços a um preço inferior ao seu valor, definido socialmente, e que acaba, portanto, prejudicando uma das partes. Nesse sentido, Durkheim teve o mérito de chamar a atenção para a influência da ética no mercado, que pode em certos casos se revelar mais forte do que a pura lógica econômica. No entanto, lamentamos que não tenha aprofundado sua análise, o 
que deixou sua teoria da avaliação social pouco consistente (Steiner, 1992). ${ }^{20}$

O papel das regras jurídicas: confiança e previsibilidade

Weber e Durkheim iniciaram uma tradição de análise sobre os vínculos entre Direito e economia, em particular a construção jurídica das relações mercantis, que hoje voltou a ser debatida. Interessante é observar que eles não tinham somente a visão, comum hoje, de Direito como regra coercitiva, mas o consideravam também um instrumento facilitador, no sentido de assegurar a confiança entre os atores econômicos.

Para Durkheim, devido à sua complexidade, o contrato, base da relação mercantil, longe de ser primitivo, só poderia surgir e se desenvolver numa época tardia da história da humanidade, pois ele supõe uma base jurídica. Mesmo na sociedade moderna, como vimos, o contrato precisa do não-contratual, ou seja, das regras formais e/ou informais que estabelecem as condições da relação entre os parceiros da troca: "é bem verdade que as relações contratuais [...] se multiplicam à medida que o trabalho social se divide. Mas [...] as relações não contratuais se desenvolvem ao mesmo tempo" (Durkheim, 1995, p. 193). Em particular, o contrato precisa do Direito que, para Durkheim, é uma instituição, isto é, um fato social, no sentido de ser exterior, coercitivo e geral; seu aspecto institucional revela-se também no fato de ele encerrar uma dimensão coletiva e de longo prazo: "Resumo de experiências numerosas e variadas, o que não podemos prever individualmente está previsto aí, o que não podemos regular aí é regulamentado, e essa regulamentação se impõe a nós, conquanto não seja nossa obra, mas da sociedade e da tradição" (Idem, p. 201). Qual seria, então, seu papel na regulamentação do mercado? O Direito contratual está na base da relação contratual e, portanto, possibilita a atividade econômica, pois, se as condições gerais de todo contrato de compra e venda ou de aluguel não fossem predefinidas, não teríamos como negociar constantemente as condições presentes e futuras do acordo e, portanto, "[...] ficaríamos imobilizados" (Idem, ibidem). O Direito permite assim economizar tempo social e reduzir os conflitos no mercado, na medida em que define os direitos e os deveres de cada um.

De maneira geral, o Direito moderno empenha-se em fazer respeitar os direitos individuais, $\mathrm{O}$ que representa uma inovação na história da humanidade. Durkheim lembra que as formas antigas de contrato, o contrato real e o solene, correspondem "[...] a um estádio da evolução social em que o direito dos indivíduos ainda não era senão fracamente respeitado. Daí resultou não serem senão mui fracamente protegidos os direitos individuais envolvidos em todo contrato" (Durkheim, 1983 , p. 180). Isso não significa que não havia punição, mas as sanções só intervinham no caso e na medida em que o contrato representava uma ameaça para a sociedade em si, ou seja, para a "autoridade pública". Pelo contrário, os interesses individuais não eram levados em conta: "não são previstos, de modo nenhum, os danos que possa causar [...]" o contrato (Idem, p. 181). Nesse sentido, o Direito moderno permite assegurar a confiança no mercado, ao punir atos desonestos: hoje, "a sanção dos contratos consiste, então, essencialmente, não em vingar a autoridade pública da desobediência, como no caso do devedor recalcitrante, mas em assegurar, às duas partes, a plena e direta realização dos direitos adquiridos" (Idem, p. 182). Ele permite, finalmente, evitar a exploração do fraco pelo forte, sobretudo no mercado de trabalho, e assegurar assim um princípio de justiça, como vimos anteriormente.

A sociologia do Direito de Weber é bem conhecida, mas raramente se faz referência à sua contribuição à sociologia econômica (Swedberg, 1998b). No entanto, várias vezes, ele cita o Direito como um pré-requisito da emergência do capitalismo ou de seu funcionamento, afirmando que a ordem econômica e a ordem jurídica estão relacionadas de maneira íntima (Weber, 1991, p. 210). Entretanto, Weber critica tanto Marx e sua determinação linear do Direito pela economia, como Stammler e sua determinação simetricamente oposta da economia pelo Direito. Weber argumenta que as relações entre ambas as esferas são com- 
plexas e que não se pode estabelecer uma causalidade simples, num ou noutro sentido (Swedberg, 1998b, p. 88). De acordo com nosso objetivo, tentaremos aqui nos concentrar sobre o papel do Direito na regulação do mercado.

No caso do Direito, a reprovação para toda violação da regra constatada no caso da convenção se caracteriza por uma "[...] coação (física ou psíquica) exercida por determinado quadro de pessoas cuja função específica consiste em forçar a observação dessa ordem ou castigar sua violação" (Weber, 1991, p. 21). O traço distintivo do Direito é, portanto, a existência deste "quadro de pessoas", constituído, na sociedade moderna, por "[...] juízes, procuradores, funcionários administrativos, executores etc." (Idem, ibidem). Na economia, ele regulamenta em particular as relações mercantis "[...] pela efetiva limitação jurídica da troca ou da liberdade na luta de preços e de concorrência, de forma geral ou para determinados círculos de pessoas ou objetos de troca" (Idem, pp. 50-51).

De maneira geral, na teoria da ação social de Weber, o Direito deve ser visto como mais um elemento, além de seus interesses e dos outros atores, que um ator econômico deve levar em conta quando toma suas decisões. Segundo Weber, as pessoas respeitam as regras jurídicas, não "por obediência sentida como dever jurídico", mas por uma variedade de motivos, indo do utilitário ao ético, passando pelo "subjetivamente convencional, pelo temor à desaprovação do mundo circundante" (Idem, pp. 210-211). Com efeito, a autoridade da ordem jurídica depende menos da existência da coerção e mais do fato de as regras jurídicas se tornarem regras tradicionais, cuja desobediência é punida pelas convenções sociais. Nesse sentido, a importância da regra jurídica na conduta social não deve ser exagerada, pois, às vezes, ela tem menos força do que o preceito religioso ou a convenção social.

Apesar disso, de acordo com Weber, a lei desempenha um papel-chave na economia de mercado, sobretudo em virtude do contrato, o que aproxima sua reflexão das idéias de Durkheim: "a economia moderna baseia-se em oportunidades adquiridas por contratos" (Idem, p. 226). E os contratos, que regulamentam as trocas e permitem criar novas relações econômicas, são em princípio garantidos "por coação jurídica" que se apóia especialmente na garantia estatal (Idem, p. 221). Weber, assim como Durkheim, desenvolve uma análise sociológica cuidadosa do contrato e mostra que, para permitir um funcionamento racional do mercado, a lei deve assegurar a "liberdade material do contrato" (Weber apud Swedberg, 1998b, p. 100). Ele analisa também as outras instituições da economia de mercado, demonstrando como o Direito é fundamental para legitimar a propriedade privada e a firma; em particular, sua análise considera as condições legais que permitiram a emergência da noção de pessoa jurídica e de empresa, como organização legalmente autônoma, isto é, cuja autonomia é garantida pelo Estado (Weber apud Swedberg, 1998b, p. 102).

O Direito permite assegurar a confiança no mercado na medida em que aumenta as chances de que os contratos sejam respeitados e de que a propriedade seja defendida. Por um lado, a regra jurídica aumenta a possibilidade de as pessoas exigirem o apoio de um aparelho coercitivo para defender seus interesses; por outro, se, nas trocas mercantis, o "interesse egoísta" "[...] atua contra a inclinação de faltar à promessa", é melhor ainda poder contar com uma garantia jurídica ${ }^{21}$ (Weber, 1991, p. 221). Não obstante a economia oferecer vários exemplos de atividades ou organizações econômicas que gozam de estabilidade e segurança sem que haja necessariamente a garantia do Direito - como a Bolsa ou os cartéis -, ele não deixa de representar um "acréscimo de segurança" na expectativa de que um determinado comportamento ocorra (Idem).

Contudo o mais importante é que a economia moderna precisa de um ambiente previsível, do qual participa o Direito, estreitamente ligado à racionalidade. "O domínio universal da relação associativa de mercado exige [...] um funcionamento do direito calculável segundo regras racionais" (Idem, p. 227, grifo do autor). Com efeito, uma das precondições para a emergência do capitalismo no Ocidente foi a existência de um "Direito racional", isto é, "calculável"; qualquer outro tipo de Direito produz constantes perturbações nas estimativas da vida econômica (Weber, 1968). O Di- 
reito racional implica a previsibilidade, ou seja, evita as surpresas, e não é arbitrário, isto é, respeita a autonomia da economia (Swedberg, 1998b, p. 104). Assim, o papel do Direito consiste essencialmente em assegurar um ambiente previsível para que os atores econômicos possam tomar suas decisões da maneira mais racional possível.

Ambos os autores insistem, portanto, na importância do Direito para manter a confiança no mercado, ao assegurar o respeito aos contratos e à propriedade privada, duas instituições fundamentais. Cada um traz ainda uma contribuição adicional e diferenciada: Durkheim lembra que o Direito permite economizar o tempo social; Weber mostra o papel do Direito na implementação de um ambiente estável e previsível.

\section{O papel do Estado: regulação econômica e difusão de valores}

No quadro de sua concepção sofisticada de embeddedness, Weber discute a influência recíproca entre a esfera econômica e a política. ${ }^{22}$ Como neste texto estamos interessados no papel do Estado na construção social do mercado, é suficiente analisarmos como Weber entendia a influência da esfera política sobre a esfera econômica. Podemos começar lembrando que o conceito de "luta" é central tanto na sociologia política weberiana como em sua sociologia econômica (Swedberg, 1998b). Contudo, o ponto-chave que diferencia ambas as esferas é a noção de violência. De fato, se o uso da violência é o monopólio do Estado num determinado território, a atividade econômica é vista como uma atividade intrinsecamente pacífica, na qual os conflitos de interesse são resolvidos pelo compromisso ou pelo poder, mas não pela violência, ao menos na sociedade moderna. No entanto, a ordem econômica é garantida, em última instância, pela ordem política: "atrás de toda economia existe um elemento coercivo - atualmente, manejado pelo Estado" (Weber, 1968, p. 10). Nesse sentido, a ampliação do mercado acarreta obrigatoriamente um reforço do poder estatal e a dissolução de todos os outros organismos de coerção, como as corporações, por exemplo. Como esse aspecto tem mais a ver com as regras jurídicas, ponto já tratado, abordaremos aqui dois outros temas.

Weber considera que o mercado prescinde de uma intervenção direta do Estado. Por um lado, ele mostra que o capitalismo de mercado se desenvolveu onde a participação direta do Estado na economia era a menor possível; foram os usos da moeda e do sistema de taxação que constituíram um ambiente favorável para a emergência da economia de mercado (Idem). Por outro lado, em sua crítica da teoria monetária de Knapp, Weber defende a idéia de que a legislação do Estado não pode influenciar muito a realidade econômica (1991). Qual seria então o papel do Estado na regulação do mercado? Em primeiro lugar, como no caso do Direito, e em grande parte por meio dele, o Estado assegura a estabilidade das regras do jogo, ou seja, a manutenção de um ambiente político e econômico previsível. Em particular, uma das atribuições do Estado é garantir a existência de um sistema monetário racional, ou seja, de não fazer flutuar a moeda em função de interesses políticos. Isso explica o fato de a dominação legal ser, das três formas de dominação, a mais adaptada à economia de mercado, devido à lógica de funcionamento da burocracia, com suas regras definidas e estáveis, e a ausência de arbitrariedade. ${ }^{23}$ De fato, "para que a exploração econômica capitalista proceda racionalmente precisa confiar em que a justiça e a administração seguirão determinadas pautas" (Idem, p. 251). Trata-se de uma visão perfeitamente compreensível dentro da sociologia econômica de Weber, pois, na medida em que o ator econômico orienta sua ação em função do comportamento dos outros atores e do contexto sociopolítico, ele precisa da maior previsibilidade possível desses comportamentos.

Em segundo lugar, o Estado, através a burocracia, participa da difusão de um ethos que tem afinidades eletivas com o ethos capitalista, ou seja, a ênfase na impessoalidade e na racionalidade. Nesse sentido, o Estado contribui para a manutenção de uma determinada mentalidade econômica, mas não é a política econômica que, direta e voluntariamente, pode influenciar o comportamento do ator econômico, pois "[...] não se cria uma 
mentalidade econômica capitalista com uma política econômica" (Weber, 1991, apud Swedberg, 1998b, p. 241). Para Weber, são os interesses dos indivíduos e não as idéias econômicas que lideram o mundo, tanto no presente como no futuro. Assim, ele afirma que uma mudança revolucionária do sistema político e, portanto, da ideologia, provavelmente não conseguiria influenciar $\mathrm{o}$ comportamento econômico, que permaneceria orientado em função dos interesses individuais. Se, na economia de mercado, os atores econômicos buscam a satisfação de seus interesses ideais ou materiais, "[...] numa economia organizada de forma socialista, não seria em princípio diferente" (Weber, 1991, p. 136). ${ }^{24}$ Contudo, na medida em que tanto a esfera burocrática como a econômica na sociedade moderna incentivam e valorizam comportamentos racionais e impessoais, a burocracia estatal acaba reforçando, até um certo limite, ${ }^{25}$ a legitimidade do mercado.

Para Durkheim, o Estado é menos um órgão executivo, que age, do que deliberativo, que pensa: "o Estado é um órgão especial encarregado de elaborar certas representações que valem para a coletividade" (Durkheim, 1983, p. 46). Durkheim afirma sua visão de Estado, e em particular sua visão das relações entre Estado e economia, opondo-se às teorias existentes. Por um lado, ele critica a visão de Spencer e dos economistas, que minimizam o papel do Estado. Talvez as funções tradicionais, como a guerra, tenham regredido, argumenta o autor, mas o Estado passou a assumir inúmeras novas funções - nas áreas de educação, saúde, infra-estrutura de transporte e de comunicação, etc. - e suas ramificações se estenderam por todo o território nacional (Durkheim, 1995). Nesse sentido, o crescimento do individualismo não implica a diminuição do papel do Estado; pelo contrário, é justamente o Estado que legitima e garante o individualismo, que afirma e faz respeitar os direitos do indivíduo. "Longe de ser antagonista do Estado, nossa individualidade moral [é], ao contrário, produto do Estado" (Durkheim, 1983, p. 63). De fato, ele "[...] tende a assegurar a individuação mais completa permitida pelo estado social. Bem longe de ser o tirano do indivíduo, ele é quem redime o indivíduo da sociedade" (Idem, p. 63). Por outro lado, não se pode considerar, na ótica dos socialistas, o Estado como "uma simples peça da máquina econômica", isto é, como um prestador de serviços para a economia (Idem, p. 66). O papel do Estado é fundamentalmente moral, ele é o "órgão por excelência da disciplina moral" (Idem, ibidem). Em vez de nos afastar do Estado, estamos nos tornando cada vez mais dependentes dele, na medida em que "[...] ele tem por encargo chamar-nos ao sentimento da solidariedade comum" (Durkheim, 1995, p. 218). ${ }^{26}$ Nesse sentido, ele influencia indiretamente o mercado, uma vez que assegura não só o respeito aos contratos e à propriedade priva$\mathrm{da}$, por meio da garantia dos direitos individuais, mas também a justiça das trocas. ${ }^{27} \mathrm{O}$ Estado não pode intervir diretamente na vida econômica, pois está por demais afastado dos particularismos setoriais, locais, etc. ${ }^{28}$ Este papel de regulação direta do mercado deve ser desempenhado pelas corporações profissionais. ${ }^{29}$

Em suma, pode-se dizer que ambos os autores têm uma postura relativamente parecida em relação ao papel do Estado. Reprovam uma intervenção direta da esfera política na economia, mesmo se por razões diferentes, mas insistem sobre sua importância na difusão dos valores da modernidade, indispensáveis para o funcionamento do mercado: racionalidade e impessoalidade, de um lado, individualismo e justiça, de outro.

\section{Considerações finais}

Apesar do caráter exploratório deste texto, podemos destacar alguns resultados fundamentais. Em ambos os autores, encontramos uma análise sociológica do mercado que insiste na dimensão socializadora da relação mercantil. Ao discutir esse tema, eles superaram muitas teorias contemporâneas a respeito. Com efeito, essa dimensão não decorre obrigatoriamente das relações pessoais, mas do fato de que, no quadro da troca mercantil, os atores econômicos não levam em conta somente seus interesses próprios, mas também o contexto institucional. 
Assim, esperamos ter conseguido mostrar que as reflexões de Durkheim e Weber contribuíram de maneira fundamental para a emergência de uma sociologia clássica do mercado. Além de terem tido o mérito de introduzir a questão do poder, hoje retomada por autores como Bourdieu e Fligstein, por exemplo, os autores orientaram sua reflexão no sentido de explicitar os aspectos sociopolíticos que caracterizam e permitem o funcionamento do mercado. De fato, ambos insistiram sobre o fato de que o ator econômico não busca unicamente seu interesse, ou melhor, os interesses e os procedimentos adequados para sua realização são definidos socialmente, isto é, pelas instituições, entre as quais são destacadas a tradição, a moral e o Direito.

Acreditamos que seja necessário aprofundar essa reflexão em três direções. Primeiro, no que diz respeito às relações entre ética e economia, somente esboçadas aqui. De fato, as idéias pioneiras de Durkheim a respeito do preço justo parecem encontrar um eco hoje nas análises desenvolvidas em torno da noção de "economia moral", elaborada inicialmente por E. P. Thompson. Em seguida, parece fundamental resgatar e aprofundar as análises iniciadas por Durkheim e Weber a respeito do papel do Estado, cuja importância reside menos numa regulação direta da economia (tema relativamente comum na sociologia econômica contemporânea), do que na difusão de valores fundamentais para o funcionamento apropriado do mercado. Finalmente, tanto para Weber como para Durkheim, o ator econômico não se comporta como um autômato, que reage aos estímulos do mercado, mas de acordo com elementos subjetivos, que não são individuais, mas sociais, isto é, enraizados no longo prazo e veiculados pelas instituições. Nesse sentido, ainda não foi feito um exame minucioso da sociologia do conhecimento implícita nas teorias desses dois autores pioneiros a partir da noção de mentalidade econômica.

\section{NOTAS}

1 Ultimamente, o Brasil vem ingressando nesta área, como testemunha, por exemplo, o número temáti- co da revista Sociedade e Estado, 17 (1) jan.-jun. 2002, dedicado à nova sociologia econômica.

2 Esta temporalidade exclui de fato Karl Marx dos fundadores da sociologia econômica clássica, apesar de ele ter feito contribuições valiosas. Cf. Steiner (2000).

3 Ver, em particular, o segundo capítulo de As Regras do método sociológico (Durkheim, 1984).

4 Infelizmente, a tradução para o português não reproduz de maneira fiel o pensamento de Durkheim. O texto original, em francês, é mais explícito a respeito da analogia que se pode fazer entre contrato e mercado: "nous passons constamment par le marché, soit pour acheter, pour vendre, ou pour louer. La plupart de nos relations avec autrui sont de nature contractuelle".

5 Chantelat critica essencialmente a análise estrutural do mercado na sociologia econômica contemporânea, que se empenha em mostrar que as relações mercantis estão inseridas em redes de relações pessoais. Ver Granovetter (1985), DiMaggio e Louch (1998) e Uzzi (1996).

6 Lembramos que Weber define luta como a atividade orientada "[...] pelo propósito de impor a própria vontade contra a resistência do ou dos parceiros" (1991, p. 23).

7 Essa dimensão política foi retomada mais recentemente no contexto da nova sociologia econômica, por autores como Fligstein (1996) e Bourdieu (1997), mas vale a pena conferir que ela não está ausente da análise durkheimiana.

8 Essa visão sociopolítica do mercado como "campo de lutas”, para falar como Bourdieu, encontra-se confirmada e reforçada por sua definição do cálculo de capital que "[...] em sua feição formalmente mais racional, pressupõe, portanto, a luta entre os bomens, uns contra os outros" (Weber, 1991, p. 57; grifo do autor).

9 Essa intuição fundamental de Weber é aprofundada num artigo clássico da nova sociologia econômica (White, 1981).

10 No espaço restrito deste texto não podemos desenvolver esse aspecto, mas o leitor pode conferir a 
análise weberiana da mediação social efetivada por meio do dinheiro, na qual Weber dialoga com Simmel e Marx (Weber, 1991).

11 Diferentemente de Durkheim, que insiste na inconsistência dos interesses, Weber considera que o interesse egoísta é uma garantia de estabilidade nas relações econômicas, pois "[...] atua contra a inclinação de faltar à promessa” (1991, p. 221).

12 Se Durkheim e Weber reconhecem que uma parte do comportamento do ator econômico pode ser explicada pela busca do interesse, eles lembram que esses interesses são definidos socialmente e não fazem parte de uma hipotética "natureza" humana.

13 Tal ameaça pode ter um impacto econômico sério: Weber, em sua análise das seitas protestantes na sociedade norte-americana, mostra até que ponto a exclusão de uma seita é economicamente penalizadora para o indivíduo, uma vez que a falta de confiança que ele inspira nos outros dificulta sua obtenção de créditos (Weber, 1982).

14 Essa reflexão continua ainda hoje pertinente, quando, por exemplo, se discute a doação/venda de sangue ou de órgãos. Zelizer $(1978,1992)$ realizou duas pesquisas fundamentais sobre a mercabilidade de crianças adotivas ou de seguro de vida.

15 Reis (2003) aponta para essa "ambigüidade fundamental" do mercado identificada por Weber. Ao mesmo tempo que legitima e incentiva o comportamento frio e egoísta de busca do interesse pessoal, o mercado encerra uma dimensão "comunal" pelo necessário reconhecimento recíproco de um conjunto de direitos comuns entre os parceiros da troca.

16 De acordo com Gislain e Steiner, "a distinção entre essas duas formas de apreciação é delicada e pouco explícita em Weber; ela corresponde a duas maneiras segundo quais os valores podem intervir. No caso de uma apreciação materialmente racional em finalidade, trata-se de uma ação (intelectual) racional em finalidade, mas baseada num critério axiológico (exigência política, ética etc.), enquanto no outro caso não se leva em conta as conseqüências da ação, como em qualquer ação racional em valor" (1995, p. 191, grifo dos autores).

17 Weber acrescenta que, "independentemente desta crítica material do resultado da gestão econômica, é também possível uma crítica ética, ascética e estética tanto da atitude econômica quanto dos meios econômicos" (1991, pp. 52-53, grifo do autor).

18 Longe do individualismo metodológico e ético dos utilitaristas, trata-se de um "individualismo moral", expressão que subentende que o "culto ao indivíduo" característico da sociedade moderna coexiste com a manutenção de regras morais compartilhadas pela coletividade. Cf. Giddens (1998).

19 Weber não concordaria com Durkheim, pois, como vimos, ele considera o mercado uma esfera na qual reinam interesses impessoais e contrários a toda ética fraterna.

20 De acordo com Steiner (1999), pesquisas empíricas realizadas recentemente confirmaram esta intuição fundamental de Durkheim.

21 Reencontramos essa diferença fundamental entre Weber e Durkheim a respeito da estabilidade do interesse.

22 Durkheim desenvolve uma concepção simples de embeddedness, na qual a esfera econômica é vista como inserida dentro da esfera social, enquanto Weber, coerente com sua recusa do determinismo unicausal, desenvolve implicitamente uma concepção mais sofisticada, na qual a esfera econômica coexiste no mesmo plano de análise das esferas sociocultural e político-jurídica (Boettke e Storr, 2002).

23 Não poderemos desenvolver aqui uma análise cuidadosa a respeito das relações existentes entre os tipos de dominação e a organização econômica em Weber. Ver a esse respeito, Swedberg (1998b).

24 Nesse ponto não se pode ter certeza se Weber, no seu desejo de criticar o socialismo, não estaria se contradizendo, já que afirma, em outro momento de sua obra, o papel preponderante das idéias na orientação dos interesses. Ou seja, será que a ideologia socialista não conseguiria reorientar os interesses individuais em direção aos interesses coletivos?

25 Essa restrição indica que há também antagonismo entre as duas esferas. Por um lado, Weber referese à incompreensão, até à hostilidade, dos funcionários públicos em relação aos atores econômicos. Por outro lado, deve-se, segundo o autor, controlar a burocracia, porque ela tende a reduzir as iniciativas econômicas privadas. 
26 Evidentemente, Durkheim deposita grandes esperanças na escola laica para a difusão dos valores morais republicanos.

27 Weber discordaria de Durkheim quanto a essa questão, na medida em que defende a tese de que não existe nenhuma afinidade eletiva entre capitalismo e democracia, isto é, que se trata de uma coincidência histórica se a sociedade moderna se caracteriza ao mesmo tempo por uma economia de mercado e pelo individualismo político (Swedberg, 1998b).

28 Essa análise do papel do Estado ilustra (brevemente) a posição de Weber e Durkheim no debate, acirrado na virada do século XIX, entre liberalismo e socialismo. Contrário ao liberalismo, que significava anomia e caos social, Durkheim via com simpatia o socialismo somente se fosse encarado essencialmente como reforma moral. Weber, por sua vez, encarava o socialismo com pessimismo, na medida em que significava um aprofundamento das restrições à liberdade humana, tendo-se em vista o crescimento da razão instrumental e do papel da burocracia pública. Cf. Fridman (1993).

29 Para uma análise do papel das corporações, com conclusões opostas, ver Durkheim (1983) e Weber (1968).

\section{BIBLIOGRAFIA}

BOETTKE, Peter \& STORR, Virgil. (2002), "Postclassical political economy: polity, society and economy in Weber, Mises and Hayek". American Journal of Economics and Sociology, 61 (1): 161-191.

BOURDIEU, Pierre. (1997), "Le champ économique". Actes de la Recherche en Sciences Sociales, 119: 48-66.

CHANTELAT, Pascal. (2002), "La nouvelle sociologie economique et le lien marchand". Revue Française de Sociologie, 43 (3): 521-556.

DiMAGGIO, Paul \& LOUCH, Hugh. (1998), "Socially embedded consumer transactions: for what kinds of purchases do people most often use networks?". American Sociological Review, 63: 619-637.
DURKHEIM, Émile. (1984), As regras do método sociológico. 11 ed. São Paulo, Editora Nacional.

. (1975), "Sociologia e ciências sociais", in A ciência social e a ação,

São Paulo, Difel, pp. 125-142 (1 ${ }^{\mathrm{a}}$ ed. 1909).

. (1983), Lições de sociologia: a moral, o direito e o Estado. São Paulo, T. A. Quei$\mathrm{rOz} / \mathrm{USP}$.

(1995), Da divisão do trabalho social. São Paulo, Martins Fontes.

FLIGSTEIN, Neil. (1996), "Markets as politics: a political-cultural approach to market institutions". American Sociological Review, 61: 656-673.

FRIDMAN, Luis Carlos. (1993), Socialismo: Émile Durkbeim, Max Weber. Rio de Janeiro, Relume Dumará.

GIDDENS, Anthony. (1998), "Durkheim e a questão do individualismo", in Politica, sociologia e teoria social: encontros com o pensamento social clássico e contemporâneo, São Paulo, Ed. da Unesp, pp. 147-168.

GISLAIN, Jean-Jacques \& STEINER, Philippe. (1995), La sociologie économique: 18901920. Paris, PUF.

GRANOVETTER, Mark. (1985), "Economic action and social structure: the problem of embeddedness". American Journal of Sociology, 91 (3): 481-510.

REIS, Bruno Pinheiro W. (2003), "O mercado e a norma: o Estado moderno e a intervenção pública na economia”. Revista Brasileira de Ciências Sociais, 52: 55-79.

STEINER, Philippe. (1992), "Le fait social économique chez Durkheim". Revue Française de Sociologie, 33 (4): 621-641.

(1999), La sociologie économique. Paris, La Découverte. 
(2000), "Marx et la sociologie économique". Cahiers Internationaux de Sociologie, 108: 57-77.

SWEDBERG, Richard. (1994), Une bistoire de la sociologie économique. Paris, Desclée de Brouwer (Trad. francesa de "Economic sociology: past and present", Current Sociology, 35 (1), n. especial, 1987).

(1998a), "Max Weber's manifesto in economic sociology". Archives Européennes de Sociologie, 39 (2): 379-398.

(1998b), Max Weber and the idea of economic sociology. Princeton, NJ, Princeton University Press.

TRIGILIA, Carlo. (2002), Sociologie économique. Paris, Armand Colin.

UZZI, Brian. (1996), "The sources and consequences of embeddedness for the economic performance of organizations: the network effect". American Sociological Review, 61 (4): 674-698.

WEBER, Max. (1960), "La morale économique des grandes religions". Archives de Sociologie des Religions, 9: 7-30 ( $1^{\text {a }}$ ed. 1920).

(1968), História geral da economia. São Paulo, Mestre Jou.

(1977), Critique of Stammler. Nova York, The Free Press.

(1982), "As seitas protestantes e o espírito do capitalismo", in

Ensaios de sociologia, Rio de Janeiro, Guanabara, pp. 347-370.

. (1991), Economia e sociedade. Brasília, Editora da UnB.

WHITE, Harrison. (1981), "Where do markets come from?". American Journal of Sociology, 87 (3): 517-547.

ZELIZER, Viviana. (1978), "Human values and the market: the case of life insurance and death in 19th-century America". American Journal of Sociology, 84: 591-610.
(1992), "Repenser le marché: la construction sociale du "marché aux bébés" aux États-Unis, 1870-1930. Actes de la Recherche en Sciences Sociales, 94: 3-26. 


\section{A CONSTRUÇÃO SOCIAL DO MERCADO EM DURKHEIM E WEBER: ANÁLISE DO PAPEL DAS INSTITUIÇÕES NA SO- CIOLOGIA ECONÔMICA CLÁSSICA}

Cécile Raud-Mattedi

\section{Palavras-chave}

Mercado; Instituições econômicas; Estado; Dukheim; Weber.

Este texto objetiva resgatar, de maneira exploratória, algumas reflexões pioneiras de Durkheim e Weber a respeito do mercado. No quadro da atual efervescência da nova sociologia econômica, argumentamos que Durkheim e Weber iniciaram o estudo sociológico do mercado em termos de construção social. De fato, ambos mostraram que os interesses econômicos e os meios adequados para sua busca são definidos socialmente, isto é, pelas instituições. Em particular, as regras tradicionais, morais e jurídicas são vistas como condicionantes básicos da regulação do mercado. Além disso, iniciando uma reflexão considerada hoje fundamental, ambos apontaram para o papel do Estado, cuja importância reside menos numa regulação direta da economia do que na difusão de valores sociais fundamentais.

\section{THE SOCIAL CONTRUCTION OF MARKET IN DURKHEIM AND WEBER: AN ANALYSIS ON THE ROLE OF INSTITU- TIONS IN THE CLASSICAL ECONOMICAL SOCIOLOGY}

Cécile Raud-Mattedi

\section{Keywords}

Market; Economic institutions; State; Durkheim; Weber.

This text aims to revive, in an exploratory manner, some of the pioneering reflections of Durkheim and Weber in relation to the market. From the viewpoint of the current excitement in the field of the new economic sociology, we argue that Durkheim and Weber were responsible for originating the sociological study of the market as a social structure. In fact, they both showed that economic interests and the means by which they may be adequately pursued are defined socially, by institutions. In particular, traditional, moral and legal rules are seen as basic conditions for the regulation of the market. Moreover, giving rise to a reflection which today is seen as fundamental, both pointed towards the role of the State, the importance of which consists less in a direct regulation of the economy than in the diffusion of essential social values.
LA CONSTRUCTION SOCIALE DU MARCHÉ DANS DURKHEIM ET WEBER: ANALYSE DU RÔLE DES INSTITUTIONS DANS LA SOCIOLOGIE ÉCONOMIQUE CLASSIQUE

Cécile Raud-Mattedi

\section{Mots-clés}

Marché; Institutions économiques; État; Durkheim; Weber.

Ce texte prétend récupérer, de façon exploratoire, quelques réflexions pionnières de Durkheim et Weber à propos du marché. Dans le cadre de l'actuelle effervescence de la nouvelle sociologie économique, nous soutenons que Durkheim et Weber ont commencé l'analyse sociologique du marché en termes de construction sociale. En fait, tous deux ont montré que les intérêts économiques et les moyens adéquats pour les atteindre sont définis socialement, c'est-à-dire, par les institutions. Les règles traditionnelles, morales et juridiques sont, en particulier, considérées comme des éléments fondamentaux de la régulation du marché. En outre, en débutant une réflexion considérée, aujourd'hui, essentielle, tous deux insistent sur le rôle de l'État, dont l'importance réside moins dans une régulation directe de l'économie que dans la diffusion de valeurs sociales fondamentales. 